OAK RIDGE

NATIONAL LABORATORY

FOR THE DEPARTMENT OF ENERGY

\title{
ASSESSMENT OF NICKEL CLAD ALLOY 214 AS THE OUTER CONTAINMENT MATERIAL OF A FISSION CHAMBER
}

\section{February 2014}

D. F. Wilson

Approved for public release.

Distribution is unlimited.

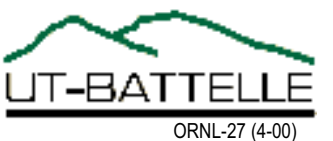




\title{
DOCUMENT AVAILABILITY
}

Reports produced after January 1, 1996, are generally available free via the U.S. Department of Energy (DOE) SciTech Connect.

Web site http://www.osti.gov/scitech

Reports produced before January 1, 1996, may be purchased by members of the public from the following source.

\author{
National Technical Information Service \\ 5285 Port Royal Road \\ Springfield, VA 22161 \\ Telephone 703-605-6000 (1-800-553-6847) \\ TDD 703-487-4639 \\ Fax 703-605-6900 \\ E-mail info@ntis.gov \\ Web site http://www.ntis.gov/support/ordernowabout.htm
}

Reports are available to DOE employees, DOE contractors,

Energy Technology Data Exchange (ETDE) representatives, and International Nuclear Information System (INIS)

representatives from the following source.

Office of Scientific and Technical Information

P.O. Box 62

Oak Ridge, TN 37831

Telephone 865-576-8401

Fax 865-576-5728

E-mail reports@adonis.osti.gov

Web site http://www.osti.gov/contact.html

This report was prepared as an account of work sponsored by an agency of the United States Government. Neither the United States Government nor any agency thereof, nor any of their employees, makes any warranty, express or implied, or assumes any legal liability or responsibility for the accuracy, completeness, or usefulness of any information, apparatus, product, or process disclosed, or represents that its use would not infringe privately owned rights. Reference herein to any specific commercial product, process, or service by trade name, trademark, manufacturer, or otherwise, does not necessarily constitute or imply its endorsement, recommendation, or favoring by the United States Government or any agency thereof. The views and opinions of authors expressed herein do not necessarily state or reflect those of the United States Government or any agency thereof. 
Materials Science and Technology Division

\title{
ASSESSMENT OF NICKEL CLAD ALLOY 214 AS THE OUTER CONTAINMENT MATERIAL OF A FISSION CHAMBER
}

D. F. Wilson

Date Published: February 2014

\author{
Prepared by \\ OAK RIDGE NATIONAL LABORATORY \\ Oak Ridge, Tennessee 37831-6285 \\ managed by \\ UT-Battelle, LLC \\ for the \\ U.S. DEPARTMENT OF ENERGY \\ under contract DE-AC05-00OR22725
}





\section{CONTENTS}

Page

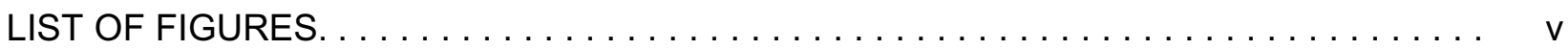

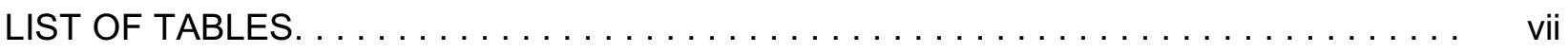

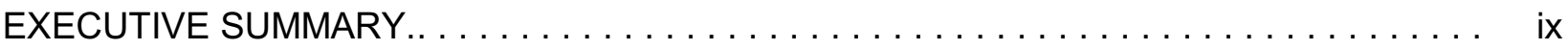

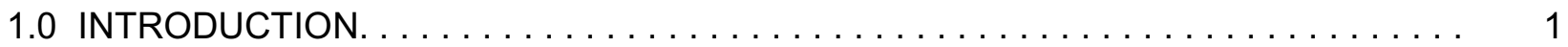

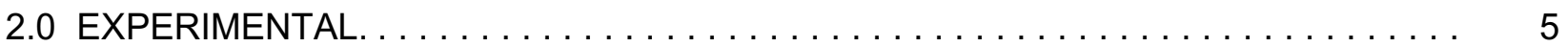

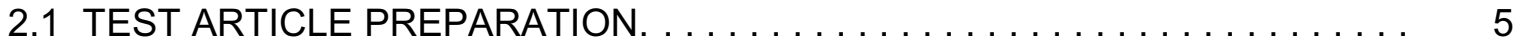

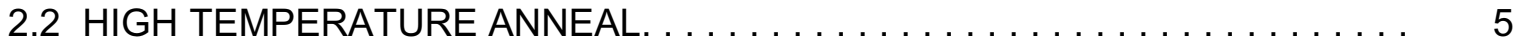

2.3 POST PROCESSING EVALUATIONS..................... 6

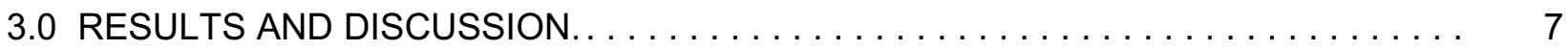

3.1 MATERIALS COMPOSITION......................... 7

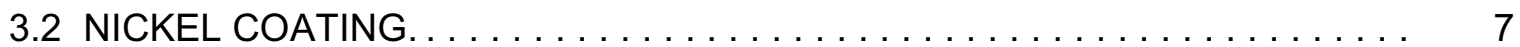

3.3 INITIAL COATING EVALUATION. $\ldots \ldots \ldots \ldots \ldots \ldots \ldots \ldots \ldots \ldots \ldots$

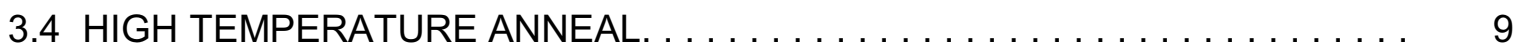

3.5 POST ANNEAL EVALUATION... . . . . . . . . . . . . . . . . . . . . . 10

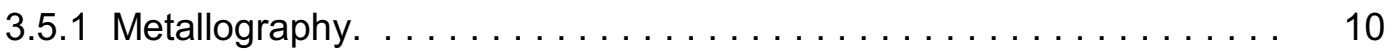

3.5 .2 Quantitative Analysis. . . . . . . . . . . . . . . . . . 10

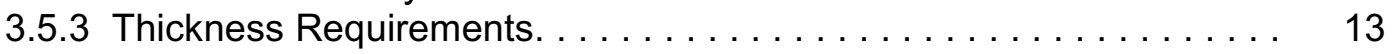

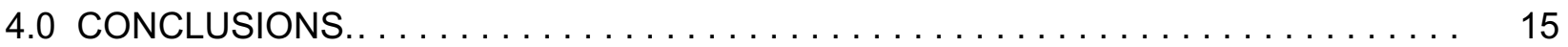

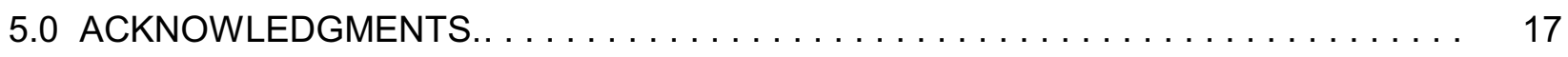

6.0 REFERENCES....................................... 19

APPENDIX A. ............................. A 

Fig. 1. Cross-sections of nickel clad Alloy 214. The specimens were clad using the MOCVD process, which was not optimized to obtain a uniform coating. .

Fig. 2. Specimens encapsulated in quartz a) before $850^{\circ} \mathrm{C}, 1000 \mathrm{~h}$ anneal; and b) after $850^{\circ} \mathrm{C}, 1000 \mathrm{~h}$ anneal. . . . . . . . . . . . . . . . . . . . . . .

Fig. 3. Typical appearance of cross-sections of nickel clad Alloy 214 after a $850^{\circ} \mathrm{C}$, 1000h anneal in argon-4\% hydrogen: a) low mag. and b) higher mag.

Some porosity has developed as a result of reordering of the morphology of the nickel layer.. . . . . . . . . . . . . . . . . . . . . . .

Fig. 4. Image showing location of the elemental line scan and position of the interface between Alloy 214 and the nickel cladding with respect to the start of the line scan .. . . . . . . . . . . . . . . . . . . . . . . . .

Fig. 5. Normalized elemental concentration (at \%) as a function of distance. The interface between Alloy 214 and the nickel cladding is at $188 \mu \mathrm{m}$. .

Fig. A.1. Image showing location of the elemental line scan across a gap in the interface and position of the interface between Alloy 214 and the nickel cladding with respect to the start of the line scan ..

Fig. A.2. Normalized elemental concentration (at \%) as a function of distance across gap interface. The interface between Alloy 214 and the nickel cladding is at $250 \mu \mathrm{m}$. 



\section{LIST OF TABLES}

TABLE

Page

Table 1. Nominal composition (wt.\%) of alloys of interest. $\ldots \ldots \ldots \ldots \ldots \ldots$

Table 2. Nominal composition (wt. \%) of Alloy 214 and measured composition of the

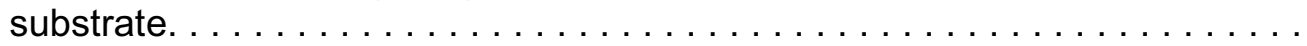

Table A.1. Elemental concentration (at. \%) across smooth interface of Alloy 214 and

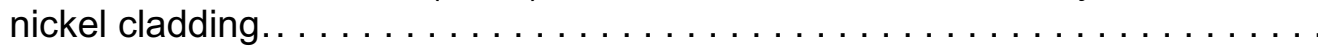

Table A2. Elemental concentration (at. \%) across gap interface of Alloy 214 and nickel cladding. . 



\section{EXECUTIVE SUMMARY}

Fission chambers are being designed to monitor in-core reactor power level via measurements of neutron flux from startup through full power. These fission chambers are being design to operate at coolant temperatures that range from $700^{\circ} \mathrm{C}$ (FLiBe-cooled) to $800^{\circ} \mathrm{C}$ (helium-cooled reactors) with some additional heating due to the presence of high fluxes of neutrons. The additional heat can increase the internal temperature of the fission chamber by approximately 200 degrees Celsius. These high temperatures and dissimilar coolants present significant and different challenges for the design of the fission chambers. Yet, it is highly desirable to have one design and manufacturing process for a fission chamber. In such a design, hightemperature creep strength and chemical compatibility with both helium with controlled levels of impurities and liquid fluoride salt environments are needed. Nickel (chemical compatibility with helium with controlled levels of impurities, and liquid fluoride salt) coated Alloy 214 (hightemperature creep strength) was evaluated for use as the external containment material of the fission chamber.

Alloy 214 was coated using vapor deposition from nickel carbonyl. The coated specimens were subjected to a high-temperature anneal at $850^{\circ} \mathrm{C}$ for $1000 \mathrm{~h}$. Post-processing evaluations included dimensional and gravimetric analyses, metallography, and electron probe micro-analysis.

The results this evaluation demonstrated:

- Vapor deposition of nickel based on the nickel carbonyl process successfully coated all surfaces of a high-temperature, nickel-based parallelepiped specimen.

- The high-temperature anneal of the coated specimen in the absence of FLiNaK 
successfully allowed for the determination of lifetimes and calculation of thickness needed for the proposed two year lifetime of the fission chamber.

- $\quad$ For the average thickness achieved by an un-optimized coating process, a lifetime of 0.55 to 0.63 y at $850^{\circ} \mathrm{C}$ can be achieved.

For a lifetime of 2 years at $850^{\circ} \mathrm{C}$, a nickel coating of thickness 3600 to $4111 \mu \mathrm{m}$ (3.6 to $4.1 \mathrm{~mm}$ ) is required; and for a lifetime of 1 year at $850^{\circ} \mathrm{C}$, a thickness of 1800 to $2100 \mu \mathrm{m}(1.8$ to $2.1 \mathrm{~mm})$ is required.

- The required nickel-coating thickness for the external surfaces of the fission chamber for the desired lifetimes can be achieved with reasonable residence times using internal heating of the chamber and optimized process parameters for the nickel carbonyl vapor deposition process. 



\subsection{INTRODUCTION}

In-core fission chambers are being designed to monitor reactor power level via measurements of neutron flux from startup through full power in flowing molten FLiBe-cooled or flowing helium-cooled high-temperature reactors. The chamber will experience external temperatures as high as $700^{\circ} \mathrm{C}$ and $800^{\circ} \mathrm{C}$ in $\mathrm{FLiBe}$-cooled and helium-cooled reactors, respectively. In addition, the internals of the chamber, which will be exposed to a noble gas-nitrogen mixture, will experience an approximate 200 degrees Celsius higher temperature due to the presence of high fluxes of neutrons.

These high temperatures present significant challenges for the mechanical design of the chambers, and the dissimilar coolant environments impose different requirements on materials compatibility. The high pressure associated with the helium-cooled environment imposes significantly higher requirements on the high-temperature creep behavior of the materials of construction as compared with the FLiBe-cooled environment. While both coolants require careful control of coolant chemistry for long-term materials compatibility, materials compatibility in the helium-cooled environment is dependent on the formation of a very slow-growing protective oxide layer on alloys, and that in FLiBe-cooled environment is highly dependent on materials being thermodynamically stable with respect to the coolant. In general, alloys that demonstrated good materials performance at high temperatures were designed for use in oxidizing environments. These alloys contain chromium and/or aluminum that provide for the high-temperature oxidation resistance. In a fluoride salt environment at high temperature, chromium and aluminum readily partition into the salt, especially if there is inadequate control of the redox potential of the salt. While there is an alloy, INOR-8, developed at ORNL for use with FLiBe and now marketed as Hastelloy $\mathbb{N}$, its use is limited to temperatures less than $704^{\circ} \mathrm{C}$ 
due to inadequate creep strength at higher temperatures. The compositions of Haynes ${ }^{\circ} 214 ®$ (Alloy 214) a high-temperature, high-strength alloy, and Hastelloy® N (Alloy N) and are presented in Table 1. As shown, there are significantly more chromium and aluminum in Alloy 214 as compared to Alloy N. The different environments associated with the two reactors strongly suggest the use of different high-temperature alloys as materials of construction of the fission chamber. However, the ability to use one design and manufacturing process for a fission chamber that can be used in either environment is highly desirable.

Table 1. Nominal composition (wt\%) of alloys of interest

\begin{tabular}{|c|c|c|c|c|c|c|c|c|c|c|c|c|c|}
\hline Alloy & $\mathbf{N i}$ & $\mathrm{Fe}$ & $\mathrm{Cr}$ & Mn & $\mathbf{S i}$ & Al & C & B & $\mathrm{Zr}$ & $\mathbf{Y}$ & Co & $\mathrm{Cu}$ & W \\
\hline $214^{*}$ & 75 & 3 & 16 & 0.5 & 0.2 & 4.5 & 0.05 & 0.01 & 0.1 & 0.01 & & & \\
\hline $\mathrm{N}^{\dagger}$ & 71 & 5 & 7 & 0.80 & 1 & $\begin{array}{l}\mathrm{Al}+\mathrm{Ti} \\
=0.35\end{array}$ & 0.08 & & & & 0.20 & 0.35 & 0.50 \\
\hline
\end{tabular}

${ }^{*}$ http://www.haynesintl.com/pdf/h3139.pdf

+ http://www.haynesintl.com/pdf/h2052.pdf

Two reports ${ }^{1,2}$, present the details of the design and materials of construction of the proposed fission chamber. These reports present the rationale for the materials and techniques for developing the fission chamber. The present work is an initial evaluation of a clad hightemperature, high creep-strength alloy. The substrate is Alloy 214 , which provides for the hightemperature creep strength, that is clad with pure nickel, which provides for fluoride salt corrosion resistance.

As reported previous, the Nickel Vapor Deposition process using nickel carbonyl gas as a precursor, which has been known for more than 100 years, provides for a pure nickel surface 
layer. $^{3}$ In this process, nickel carbonyl gas is introduced into a deposition chamber at $50^{\circ} \mathrm{C}$ and is decomposed into pure nickel and carbon monoxide at temperatures close to $175^{\circ} \mathrm{C}$, as shown in the equation (1):

$$
\mathrm{Ni}(\mathrm{CO})_{4}=\mathrm{Ni}+4 \mathrm{CO}
$$





\subsection{EXPERIMENTAL}

\subsection{TEST ARTICLE PREPARATION}

Specimens of Alloy 214 of approximate dimensions 0.15 by 1.01 by $1.90 \mathrm{~cm}$, in thickness, width and length respectively, with a hole drilled at one end, were machined, stamped with identification marks, dimensioned, weighed, cleaned and shipped to CVRM Corporation, Toronto, Ontario, Canada, for nickel coating via a vapor deposition process. Also, one specimen was shipped to Dirats Laboratories, Westfield, MA for bulk chemical analysis.

At CVRM Corporation, the specimens were degreased using Aquanox, rinsed in de-ionized water and dried at room temperature. A red silicone sheet was cut to mask the heating plate and to prevent nickel deposition on the plate. Eight specimens were place on the heating plate inside cut-outs in the red silicone sheet. The chamber was pressure tested and then sparged first with argon, and then carbon monoxide. The heating plate was raised to a temperature of $175^{\circ} \mathrm{C}$ with temperature control facilitated with thermocouples placed next to the specimens. Gaseous nickel carbonyl was introduced from the top of the deposition chamber and deposition was continued for approximately 40 minutes. After the initial deposition was completed, nickel carbonyl and carbon monoxide was sparged from the chamber, and the specimens were cooled and flipped to the other side. The chamber was closed, sparged, and the coating procedure was repeated. After sparging and cooling to room temperature, the coated specimens were removed from the chamber, placed in plastic bags, and shipped to ORNL.

\subsection{HIGH TEMPERATURE ANNEAL}

Nickel coated specimens were sealed in quartz under approximately 0.10 atm of argon- $4 \%$ hydrogen mixture. The argon- $4 \%$ hydrogen mixture was employed to prevent oxidation of the 
specimens during the high temperature anneal. The quartz ampoule was placed in an air furnace, heated to $850^{\circ} \mathrm{C}$, and maintained at temperature for $1000 \mathrm{~h}$. One thousand hours was considered to be sufficient time to allow for establishing detectable travel-distances of the diffusing elements. At the end of $1000 \mathrm{~h}$, the power to the furnace was turned off, the quartz ampoule was pulled from the furnace and allowed to air cool.

\subsection{POST PROCESSING EVALUATIONS}

Post-processing (coating and high-temperature anneal) evaluations included dimensional and gravimetric analyses, metallographic preparation of specimens, optical microscopy, and elemental chemical analyses using an Electron Probe Micro-analyzer (EPMA), JEOL JX-8200, operated at $15 \mathrm{kV}$ and at probe current of $50 \mathrm{nA}$. 


\subsection{RESULTS AND DISCUSSION}

\subsection{MATERIALS COMPOSITION}

The evaluated composition of the substrate material is presented in Table 2. As shown, the substrate used in this evaluation has a composition that is characteristic of Alloy 214 . The larger differences between nominal and measured compositions occur for elements given as maximum amount allowed in the alloy. The small amount of cobalt (most likely from the nickel source) will need to be considered in evaluating post in-reactor exposure operations.

Table 2. Nominal composition (wt\%) of Alloy 214 and measured composition of the substrate

\begin{tabular}{lccccccccccccc}
\hline Alloy & Ni & Fe & Cr & Mn & Si & Al & C & B & Zr & Y & Co & V & O+N \\
\hline Nominal $^{*}$ & 75 & 3 & 16 & $0.5^{\dagger}$ & $0.2^{\dagger}$ & 4.5 & 0.05 & $0.01^{\dagger}$ & $0.1^{\dagger}$ & 0.01 & & & \\
Measured $^{\ddagger}$ & Bal & 3.47 & 15.99 & 0.17 & 0.05 & 4.51 & 0.037 & & 0.03 & & 0.01 & 0.01 & 0.0029 \\
\hline
\end{tabular}

* http://www.haynesintl.com/pdf/h3139.pdf

+ Maximum

‡ Dirats Test Report \# R569203, dated Jul 08, 2013

\subsection{NICKEL COATING}

CVRM Corporation employed specimens with a small hole at one end, matching the dimension of those received from ORNL, to establish the initial parameters for complete encapsulation of the specimens using the Nickel Vapor Deposition process. Complete encapsulation was a criterion for high temperature testing in the presence of FLiNaK. The first series of tests was conducted in a vertical chamber with the suspended specimens heated by radiant heat from the walls of the reactor, which was held at $210^{\circ} \mathrm{C}$. Nickel carbonyl gas was introduced from the top of the deposition chamber. After several hours of deposition, the chamber was opened and coated specimens were examined. The thickness of deposited nickel was calculated from the 
weight gain of the specimen and its surface area. It was determined that most of the deposition occurred on the walls of the reactor and not on the specimens. Hence, a revised procedure (described early) was developed that involved coating one side of the specimens while it was being heated on a hot plate at $175^{\circ} \mathrm{C}$, flipping the specimen over, and repeating the coating process.

\subsection{INITIAL COATING EVALUATION}

Cross-sections of a nickel clad Alloy 214 specimen are presented in Fig. 1. As shown, the coating process, while not optimized for a uniform coating thickness, readily follows the contours of the specimens. Gaps between the nickel coatings and the substrates were observed. In some regions, these gaps were much wider than would be expected from that due to the differences in coefficient of expansion between nickel and the substrate alloy, and the thickness of native oxide on the specimen surface. Prior to the deposition process, no attempt was made to remove the native oxide on the surface of the specimens. As there was excellent interfacial contact in most regions and the substrate was completely encapsulated in nickel, the decision was made to proceed with a high-temperature anneal.

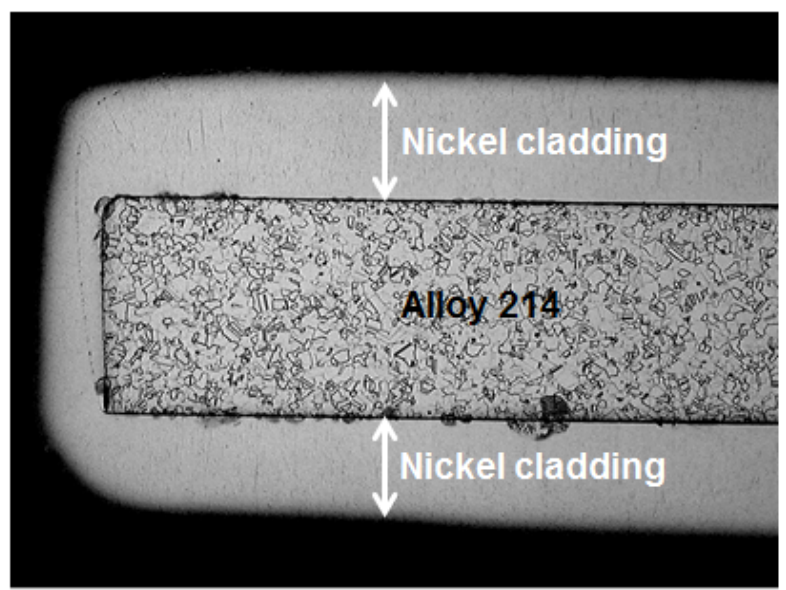

13-1840-01

$\stackrel{20 x}{2} 200 \mu \mathrm{m}$

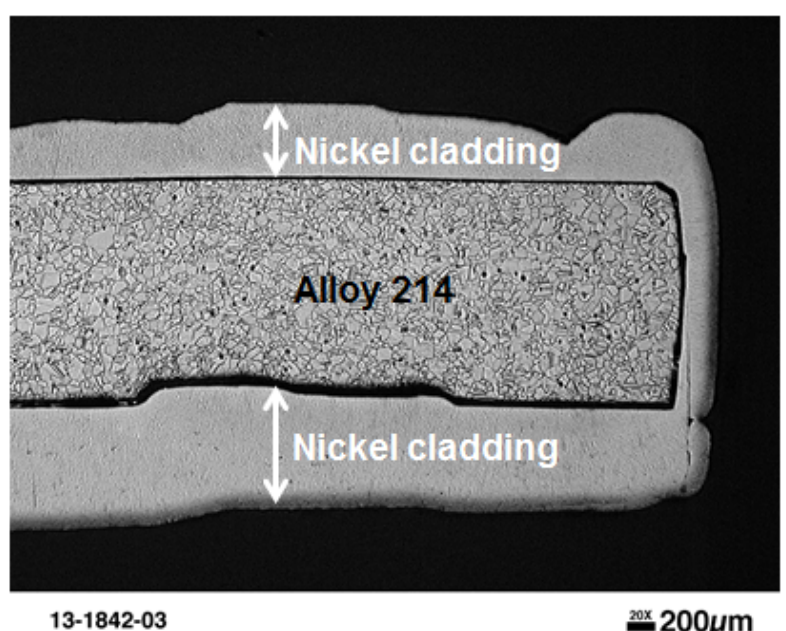

Fig. 1. Cross-sections of nickel clad Alloy 214. The specimens were clad using the MOCVD process, which was not optimized to obtain a uniform coating. 


\subsection{HIGH TEMPERATURE ANNEAL}

The initial intent was to expose the specimens to FLiNaK salt at high temperature in individual molybdenum capsules. Unforeseen and unfortunate events voided the subcontractor ability to provide capsules loaded with clean FLiNaK in a timely manner. This forced the abandonment FLiNaK testing in the interest of meeting the programmatically mandated schedule. Therefore, the decision was made to anneal the nickel-clad Alloy 214 specimens in quartz in an $\mathrm{Ar}-\mathrm{H}_{2}$ atmosphere, which would prevent oxidation of the specimen. Although this approach does not allow for a constant chemical activity at the nickel/salt interface as a result of partitioning of diffusing elements into the salt, it permits a determination of diffusion distances. The specimens, sealed in quartz, are shown in Fig. 2. After the anneal, the outside of the quartz

ampoule, shown in Fig. 2 b), had undergone some devitrification (a whitish byproduct) in the air environment of the furnace. There were no apparent effects inside the ampoule.

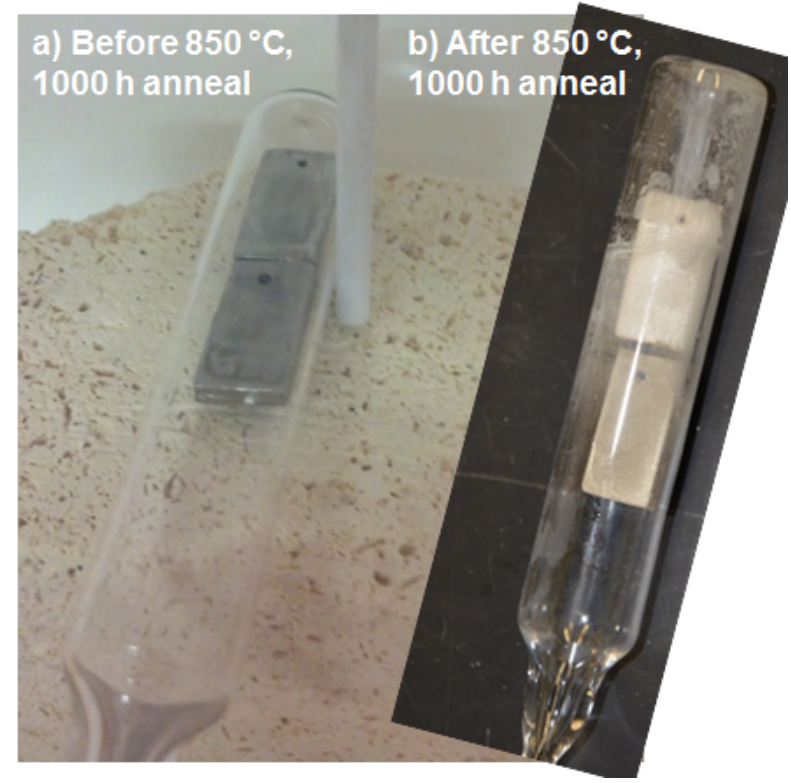

Fig. 2. Specimens encapsulated in quartz a) before $850^{\circ} \mathrm{C}, 1000 \mathrm{~h}$ anneal; and b) after $850^{\circ} \mathrm{C}, 1000 \mathrm{~h}$ anneal. 


\subsection{POST ANNEAL EVALUATION}

\subsubsection{Metallography}

Cross-sections of the nickel coated Haynes 214 specimen are presented in Fig. 3. As shown, the outer nickel layer has developed some porosity as a result of reordering of its morphology. This significant change in morphology (compare Fig. 1 to Fig. 3 ) is expected, as this anneal was the first exposure of the nickel coat to high temperature $\left(850^{\circ} \mathrm{C}\right)$. The average thickness of the coating before the anneal was $1036 \mu \mathrm{m}$ and the average thickness of the coating after the anneal was $1211 \mu \mathrm{m}$. An average of these two averages was used for calculation of coating lifetimes.

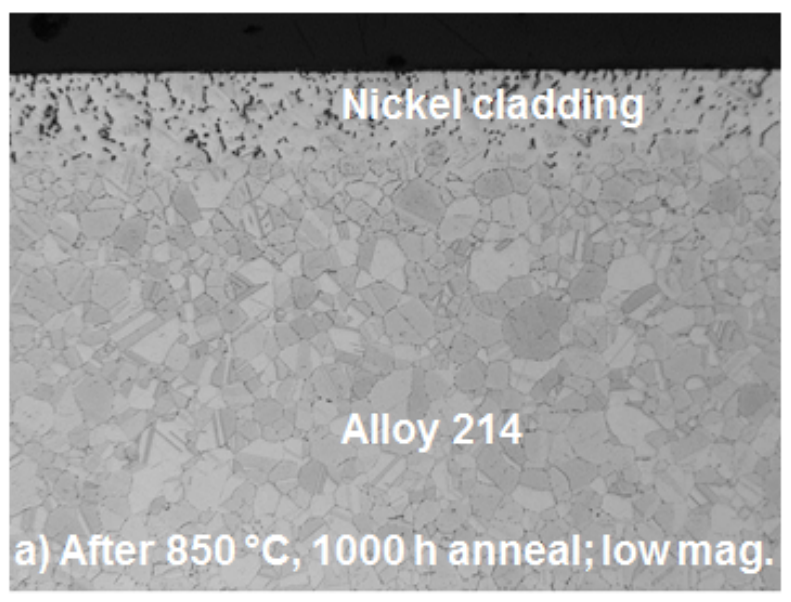

14-0203-13

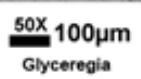

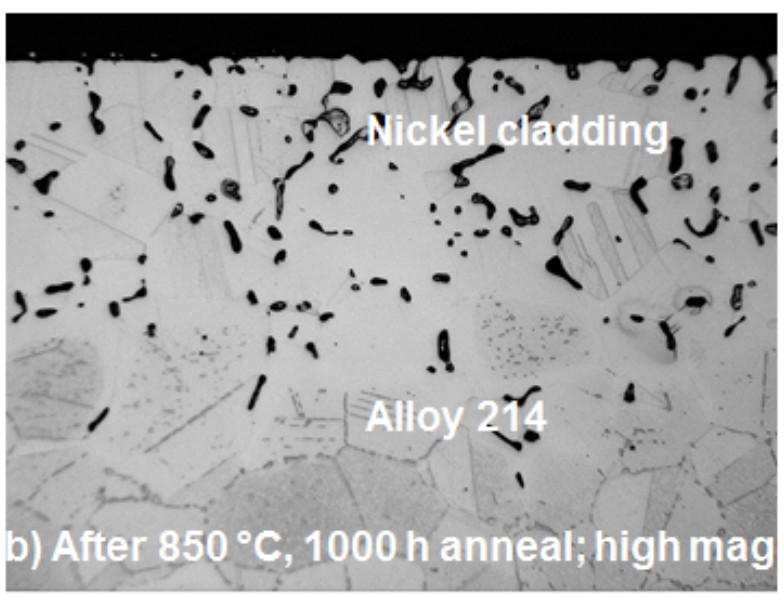

14-0203-17

Fig. 3. Typical appearance of cross-sections of nickel clad Alloy 214 after a $850^{\circ} \mathrm{C}$, $1000 \mathrm{~h}$ anneal in argon-4\% hydrogen: a) low mag. and b) higher mag. Some porosity has developed as a result of reordering of the morphology of the nickel layer.

\subsubsection{Quantitative Analysis}

The location of the elemental line scan (red arrow) and the distance to the interface between Alloy 214 and the nickel cladding from the starting point of the line scan (blue arrow) are shown 
in Fig. 4. The associated chemical information, obtained via wavelength-dispersive spectroscopy using an EPMA, is presented in Fig. 5 (The normalized atom percentage data are presented in Appendix A). As shown, the elemental concentration of the diffusing species, $\mathrm{Cr}$, $\mathrm{Al}$, and Fe, decreased within the base alloy within a short distance of the interface and no diffusing species arrived at the nickel/argon-4\%hydrogen interface. Hence, the results are applicable to fluoride salt-cooled and the helium gas-cooled nuclear reactors. Chemical data were also obtained for a line scan that included a gap between the substrate and the nickel coating. These normalized atom percentage data and associated graph and image of the microstructure at the scan line are presented in Appendix A. The gap in the interface between the substrate and coating resulted in a much more rapid decrease in diffusing chemical species with distance.

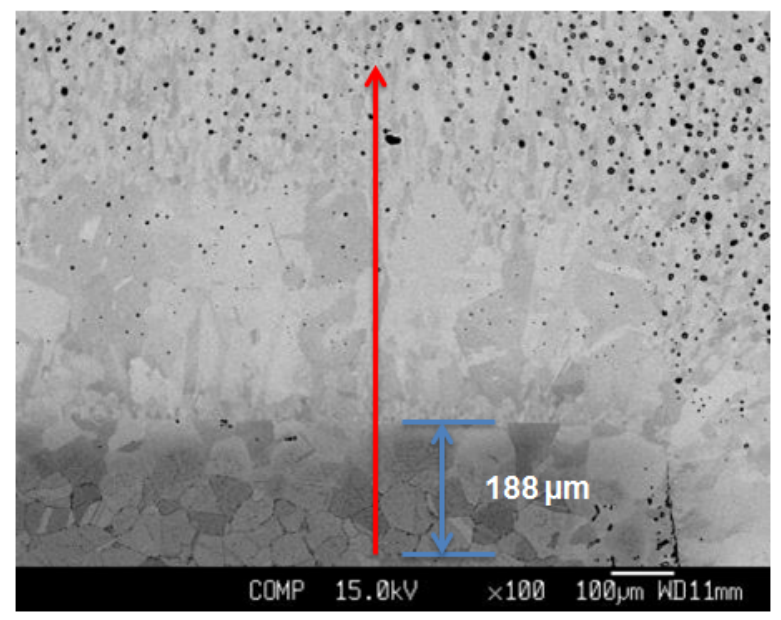

Fig. 4. Image showing location of the elemental line scan (red arrow) and position of the interface between Alloy 214 and the nickel cladding with respect to the start of the line scan (blue arrow). 


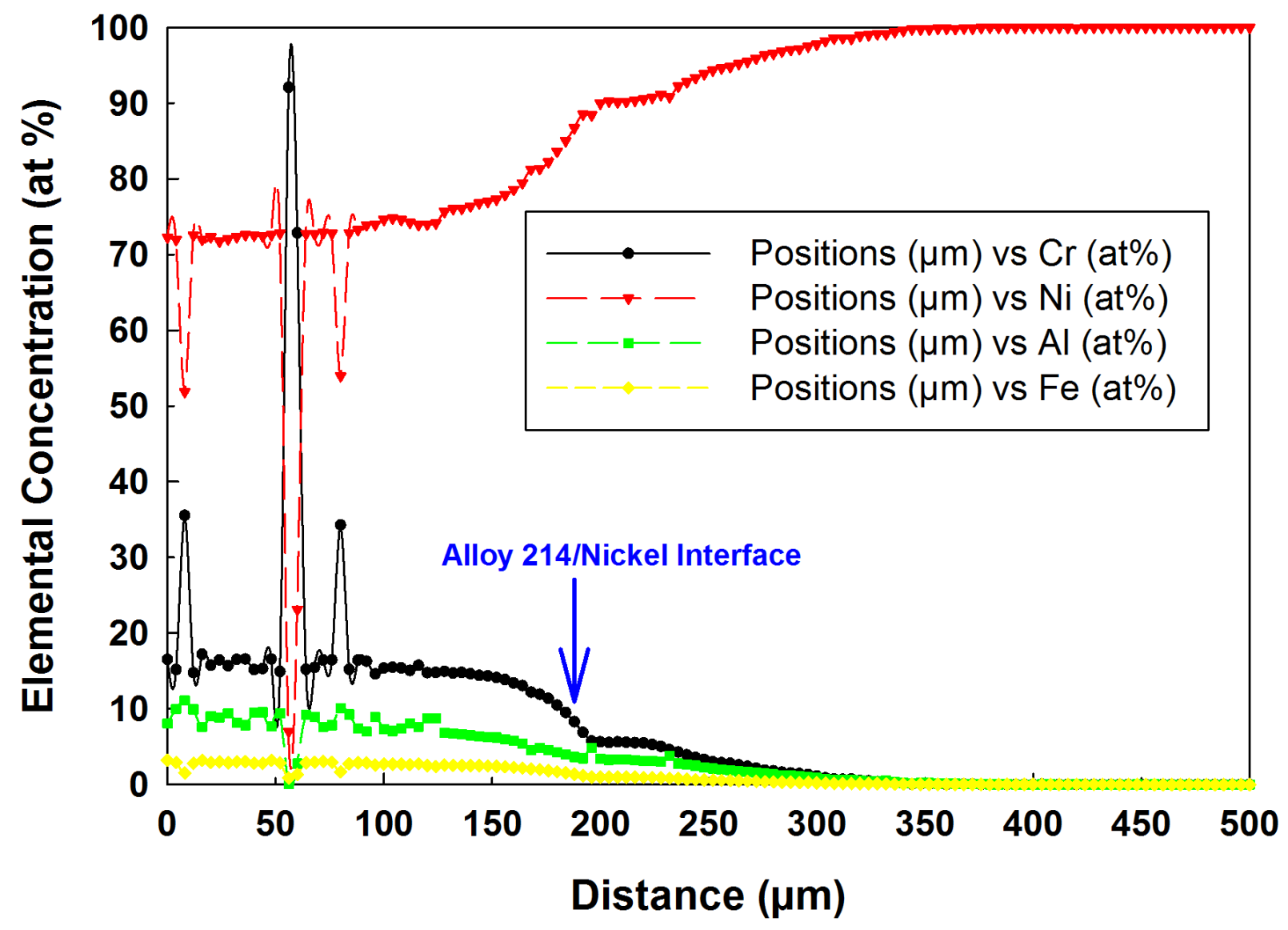

Fig. 5. Normalized elemental concentration (at \%) as a function of distance. The interface between Alloy 214 and the nickel cladding (blue arrow) is at $188 \mu \mathrm{m}$.

As presented in Fig. 5, post-interface location, the elemental concentrations decreased in the nickel cladding to zero within 204 to 236 microns as measured with respect to the original Alloy214/nickel interface (blue arrow in Fig. 5). Using data from prior work ${ }^{4}$ for chromium tracer $\left(\mathrm{Cr}^{51}\right)$ diffusion into Inconel (not stated but most likely Inconel 600) and INOR-8 (Alloy N), nickel chromium alloys, in the temperature range of 600 to $900^{\circ} \mathrm{C}$, a distance of 18 microns (11 to 13 times smaller) can be calculated. Also, the authors showed a decrease in the diffusion rate of chromium with increasing chromium additions to nickel-based alloys. The larger transport 
distance in the present work is due to several factors including reorientation of the morphology of the pure nickel cladding and development of porosity (contributes to the increase in thickness reported earlier) due to the high temperature anneal, and differences in cross-interactions between the diffusing species into pure nickel as compared to chromium diffusing into nickelchromium alloys. At $850^{\circ} \mathrm{C}$ (less than $2 / 3$ the melting point of nickel), increased surface area for rapid surface diffusion, as compared to volume diffusion, would significant increase the diffusion rates.

\subsubsection{Thickness Requirements}

The un-optimized nickel carbonyl coating process resulted in an average coating thickness (coating before anneal and coating after anneal) of $1124 \mu \mathrm{m}(1.124 \mathrm{~mm})$. Using this average thickness and a distance range of 204 to 236 microns for diffusing elements concentration to fall to zero, results in a lifetime [time for diffusing elements to arrive at the external nickel surface (nickel/gas interface)] of 0.55 to $0.63 \mathrm{y}$. Alternatively, a lifetime of 2 years at $850^{\circ} \mathrm{C}$ requires nickel coating of thickness 3600 to $4111 \mu \mathrm{m}$ (3.6 to $4.1 \mathrm{~mm}$ ); and that of 1 year at $850^{\circ} \mathrm{C}$, a thickness of 1800 to $2100 \mu \mathrm{m}(1.8$ to $2.1 \mathrm{~mm})$. Using internal heating of the chamber and optimized process parameter for the nickel carbonyl vapor deposition process, these coating thicknesses can be achieved with reasonable residence times. 



\subsection{CONCLUSIONS}

The use of a nickel coated high-temperature material (Alloy 214) as the enclosure of the fission chamber was evaluated. The results this evaluation demonstrated:

Vapor deposition of nickel based on the nickel carbonyl process successfully coated all surfaces of a high-temperature, nickel-based parallelepiped specimen. Hence, the process is well suited to coating the outer nickel-based alloy enclosure of the fission chamber.

- The high-temperature anneal of the coated specimen in the absence of FLiNaK successfully allowed for the determination of lifetimes and calculation of thickness needed for the proposed two year lifetime of the fission chamber. A lifetime of 2 years at $850^{\circ} \mathrm{C}$ requires nickel coating of thickness 3600 to $4111 \mu \mathrm{m}(3.6$ to $4.1 \mathrm{~mm}$ ).

- During the high-temperature anneal, no diffusing species reached the nickel/argon-4\% hydrogen interface. Hence, the distribution of diffusing species is characteristic of a non-equilibrium distribution that could be established if $\mathrm{Cr}, \mathrm{Al}$, and $\mathrm{Fe}$ were being leached from the nickel by molten salt at least as fast as they arrived at the nickel/molten salt interface. 



\subsection{ACKNOWLEDGMENTS}

The contributions of Tyson Jordan (metallography), Donovan Leonard (EPMA), Tracie Lowe (SEM), and Adam Willoughby (procurement of materials and services, and materials

preparation) are gratefully acknowledged. 



\subsection{REFERENCES}

1. Z. W. Bell, M. J. Harrison, D. E. Holcomb, C. L. Britton, N. D. Bull, R. J. Warmack, M. J. Lance, K. J. Leonard, T. Katoh, R. G. Miller, R. T. Mayes, D. R. Giuliano, and A. M. Aaron, Materials Selection for a High-Temperature Fission Chamber, ORNL/LTR-2012/331, August 2012, Oak Ridge National Laboratory, Oak Ridge, Tennessee.

2. Z. W. Bell, R. J. Warmack, N. S. Kulkarni, R. G. Miller, D. F. Wilson, R. T. Mayes, D. R. Giuliano, A. M. Aaron, and D. M. Manofsky, Preliminary Design for a High Temperature Fission Chamber, ORNL/TM-2013/435, September 2013, Oak Ridge National Laboratory, Oak Ridge, Tennessee.

3. G. Muralidharan, D. F. Wilson, L. R. Walker, M. L. Santella, and D. E. Holcomb, Cladding Alloys for Fluoride Salt Compatibility, ORNL/TM-2011/95, May 25, 2011, Oak Ridge National Laboratory, Oak Ridge, Tennessee.

4. R. B. Evans, J. H. DeVan, and G. M. Watson, Self-Diffusion of Chromium in Nickel-Based Alloys, ORNL-2982, January 20, 1961, Oak Ridge National Report, Oka Ridge, Tennessee. 



\section{APPENDIX A}

The elemental concentrations across the smooth interface are presented in Table A.1.

Table A.1. Elemental concentration (at. \%) across smooth interface of Alloy 214 and nickel cladding

\begin{tabular}{lrrrrr}
\hline Position & \multicolumn{5}{c}{ Element } \\
\cline { 2 - 6 }$(\boldsymbol{\mu m})$ & $\mathbf{C r}$ & \multicolumn{1}{c}{ Ni } & \multicolumn{1}{c}{ Al } & Fe & Total \\
\hline 0 & 16.489 & 72.258 & 8.041 & 3.212 & 100 \\
4 & 15.161 & 71.966 & 9.986 & 2.887 & 100 \\
8 & 35.524 & 51.868 & 11.093 & 1.516 & 100 \\
12 & 14.749 & 72.540 & 9.929 & 2.782 & 100 \\
16 & 17.197 & 71.989 & 7.628 & 3.186 & 100 \\
20 & 15.733 & 72.342 & 9.024 & 2.902 & 100 \\
24 & 16.450 & 71.739 & 8.837 & 2.973 & 100 \\
28 & 15.658 & 72.050 & 9.427 & 2.865 & 100 \\
32 & 16.501 & 72.329 & 8.179 & 2.991 & 100 \\
36 & 16.565 & 72.579 & 7.828 & 3.028 & 100 \\
40 & 15.167 & 72.534 & 9.496 & 2.803 & 100 \\
44 & 15.291 & 72.413 & 9.524 & 2.772 & 100 \\
48 & 16.569 & 72.575 & 7.666 & 3.191 & 100 \\
52 & 14.914 & 72.823 & 9.419 & 2.843 & 100 \\
56 & 92.058 & 7.025 & 0.078 & 0.839 & 100 \\
60 & 72.850 & 23.086 & 2.744 & 1.320 & 100 \\
64 & 15.183 & 72.736 & 9.200 & 2.881 & 100 \\
68 & 15.450 & 72.698 & 8.933 & 2.919 & 100 \\
72 & 16.416 & 72.901 & 7.627 & 3.057 & 100 \\
76 & 16.456 & 72.783 & 7.829 & 2.933 & 100 \\
80 & 34.270 & 53.968 & 10.078 & 1.684 & 100 \\
84 & 15.189 & 72.833 & 9.256 & 2.721 & 100 \\
88 & 16.410 & 73.285 & 7.421 & 2.884 & 100 \\
92 & 16.258 & 73.907 & 6.982 & 2.853 & 100 \\
96 & 14.592 & 73.964 & 8.900 & 2.544 & 100 \\
100 & 15.354 & 74.628 & 7.313 & 2.704 & 100 \\
104 & 15.459 & 74.792 & 7.085 & 2.665 & 100 \\
108 & 15.372 & 74.590 & 7.374 & 2.664 & 100 \\
112 & 15.057 & 74.248 & 8.078 & 2.618 & 100 \\
116 & 15.719 & 73.939 & 7.617 & 2.725 & 100 \\
120 & 14.746 & 73.980 & 8.766 & 2.509 & 100 \\
124 & 14.782 & 74.118 & 8.741 & 2.360 & 100 \\
128 & 14.932 & 75.668 & 6.851 & 2.549 & 100 \\
132 & 14.692 & 76.031 & 6.760 & 2.518 & 100 \\
136 & 14.791 & 76.080 & 6.619 & 2.510 & 100 \\
140 & 14.613 & 76.388 & 6.494 & 2.505 & 100 \\
144 & 14.377 & 76.776 & 6.359 & 2.487 & 100
\end{tabular}




\begin{tabular}{lrcccr}
\hline Position & \multicolumn{5}{c}{ Element } \\
\cline { 2 - 6 }$(\boldsymbol{\mu m})$ & $\mathbf{C r}$ & $\mathbf{N i}$ & Al & Fe & Total \\
\hline 148 & 14.320 & 76.985 & 6.257 & 2.438 & 100 \\
152 & 14.100 & 77.300 & 6.212 & 2.389 & 100 \\
156 & 13.842 & 77.891 & 5.944 & 2.324 & 100 \\
160 & 13.390 & 78.587 & 5.772 & 2.252 & 100 \\
164 & 13.031 & 79.430 & 5.376 & 2.162 & 100 \\
168 & 12.198 & 81.256 & 4.515 & 2.031 & 100 \\
172 & 11.908 & 81.317 & 4.830 & 1.946 & 100 \\
176 & 11.367 & 82.224 & 4.565 & 1.844 & 100 \\
180 & 10.475 & 83.608 & 4.238 & 1.679 & 100 \\
184 & 9.489 & 85.009 & 3.973 & 1.529 & 100 \\
188 & 8.266 & 86.721 & 3.652 & 1.361 & 100 \\
192 & 6.871 & 88.529 & 3.445 & 1.156 & 100 \\
196 & 5.738 & 88.409 & 4.857 & 0.996 & 100 \\
200 & 5.609 & 89.995 & 3.408 & 0.988 & 100 \\
204 & 5.522 & 90.239 & 3.250 & 0.989 & 100 \\
208 & 5.613 & 90.118 & 3.273 & 0.995 & 100 \\
212 & 5.556 & 90.180 & 3.295 & 0.969 & 100 \\
216 & 5.498 & 90.350 & 3.185 & 0.968 & 100 \\
220 & 5.483 & 90.507 & 3.086 & 0.924 & 100 \\
224 & 5.263 & 90.717 & 3.095 & 0.925 & 100 \\
228 & 5.004 & 91.118 & 2.994 & 0.883 & 100 \\
232 & 4.585 & 90.821 & 3.779 & 0.815 & 100 \\
236 & 4.265 & 92.208 & 2.755 & 0.772 & 100 \\
240 & 3.890 & 92.800 & 2.604 & 0.705 & 100 \\
244 & 3.555 & 93.340 & 2.466 & 0.640 & 100 \\
248 & 3.301 & 93.831 & 2.272 & 0.596 & 100 \\
252 & 2.988 & 94.359 & 2.098 & 0.555 & 100 \\
256 & 2.861 & 94.625 & 1.991 & 0.524 & 100 \\
260 & 2.795 & 94.800 & 1.885 & 0.520 & 100 \\
264 & 2.593 & 95.212 & 1.724 & 0.470 & 100 \\
268 & 2.376 & 95.500 & 1.672 & 0.452 & 100 \\
272 & 2.135 & 95.912 & 1.545 & 0.407 & 100 \\
276 & 1.858 & 96.330 & 1.451 & 0.361 & 100 \\
280 & 1.785 & 96.553 & 1.323 & 0.339 & 100 \\
284 & 1.626 & 96.834 & 1.229 & 0.312 & 100 \\
288 & 1.501 & 97.053 & 1.154 & 0.292 & 100 \\
292 & 1.457 & 97.150 & 1.137 & 0.256 & 100 \\
296 & 1.287 & 97.496 & 0.960 & 0.258 & 100 \\
300 & 1.098 & 97.756 & 0.923 & 0.223 & 100 \\
304 & 0.871 & 98.202 & 0.735 & 0.193 & 100 \\
308 & 0.694 & 98.547 & 0.619 & 0.140 & 100 \\
312 & 0.671 & 98.589 & 0.616 & 0.124 & 100 \\
316 & 0.691 & 98.531 & 0.639 & 0.140 & 100 \\
320 & 0.510 & 98.887 & 0.500 & 0.104 & 100 \\
324 & 0.466 & 98.989 & 0.432 & 0.114 & 100 \\
328 & 0.367 & 99.128 & 0.407 & 0.098 & 100 \\
332 & 0.222 & 99.127 & 0.568 & 0.083 & 100 \\
336 & 0.253 & 99.409 & 0.289 & 0.049 & 100
\end{tabular}




\begin{tabular}{lrrrrr}
\hline Position & \multicolumn{5}{c}{ Element } \\
\cline { 2 - 6 }$(\boldsymbol{\mu m})$ & $\mathbf{C r}$ & \multicolumn{1}{c}{ Ni } & Al & Fe & Total \\
\hline 340 & 0.167 & 99.583 & 0.214 & 0.036 & 100 \\
344 & 0.030 & 99.775 & 0.144 & 0.051 & 100 \\
348 & 0.036 & 99.754 & 0.185 & 0.025 & 100 \\
352 & 0.034 & 99.766 & 0.180 & 0.021 & 100 \\
356 & 0.036 & 99.849 & 0.098 & 0.017 & 100 \\
360 & 0.000 & 99.841 & 0.136 & 0.023 & 100 \\
364 & 0.055 & 99.826 & 0.095 & 0.024 & 100 \\
368 & 0.042 & 99.907 & 0.040 & 0.012 & 100 \\
372 & 0.032 & 99.879 & 0.079 & 0.010 & 100 \\
376 & 0.000 & 99.948 & 0.040 & 0.012 & 100 \\
380 & 0.000 & 99.992 & 0.008 & 0.000 & 100 \\
384 & 0.000 & 99.994 & 0.006 & 0.000 & 100 \\
388 & 0.000 & 99.949 & 0.033 & 0.018 & 100 \\
392 & 0.000 & 100.000 & 0.000 & 0.000 & 100 \\
396 & 0.000 & 99.995 & 0.000 & 0.005 & 100 \\
400 & 0.000 & 99.998 & 0.000 & 0.003 & 100 \\
404 & 0.017 & 99.974 & 0.004 & 0.005 & 100 \\
408 & 0.000 & 99.987 & 0.013 & 0.000 & 100 \\
412 & 0.000 & 100.000 & 0.000 & 0.000 & 100 \\
416 & 0.000 & 99.999 & 0.000 & 0.001 & 100 \\
420 & 0.000 & 99.924 & 0.076 & 0.000 & 100 \\
424 & 0.000 & 100.000 & 0.000 & 0.000 & 100 \\
428 & 0.000 & 99.999 & 0.000 & 0.001 & 100 \\
432 & 0.000 & 99.991 & 0.000 & 0.009 & 100 \\
436 & 0.000 & 99.989 & 0.000 & 0.011 & 100 \\
440 & 0.000 & 100.000 & 0.000 & 0.000 & 100 \\
444 & 0.000 & 100.000 & 0.000 & 0.000 & 100 \\
448 & 0.000 & 99.990 & 0.010 & 0.000 & 100 \\
452 & 0.000 & 100.000 & 0.000 & 0.000 & 100 \\
456 & 0.000 & 99.993 & 0.008 & 0.000 & 100 \\
460 & 0.000 & 100.000 & 0.000 & 0.000 & 100 \\
464 & 0.000 & 100.000 & 0.000 & 0.000 & 100 \\
468 & 0.000 & 100.000 & 0.000 & 0.000 & 100 \\
472 & 0.000 & 100.000 & 0.000 & 0.000 & 100 \\
476 & 0.000 & 99.990 & 0.000 & 0.010 & 100 \\
480 & 0.000 & 100.000 & 0.000 & 0.000 & 100 \\
484 & 0.000 & 100.000 & 0.000 & 0.000 & 100 \\
488 & 0.000 & 100.000 & 0.000 & 0.000 & 100 \\
492 & 0.000 & 99.997 & 0.000 & 0.003 & 100 \\
496 & 0.000 & 100.000 & 0.000 & 0.000 & 100 \\
500 & 0.000 & 100.000 & 0.000 & 0.000 & 100 \\
504 & 0.000 & 100.000 & 0.000 & 0.000 & 100 \\
508 & 0.000 & 100.000 & 0.000 & 0.000 & 100 \\
512 & 0.000 & 100.000 & 0.000 & 0.000 & 100 \\
516 & 0.000 & 100.000 & 0.000 & 0.000 & 100 \\
524 & 0.000 & 100.000 & 0.000 & 0.000 & 100 \\
528 & 0.000 & 100.000 & 0.000 & 0.000 & 100 \\
& 0.000 & 100.000 & 0.000 & 0.000 & 100
\end{tabular}




\begin{tabular}{|c|c|c|c|c|c|}
\hline \multirow{2}{*}{$\begin{array}{l}\text { Position } \\
(\mu \mathrm{m})\end{array}$} & \multicolumn{5}{|c|}{ Element } \\
\hline & $\mathrm{Cr}$ & $\mathrm{Ni}$ & $\mathrm{Al}$ & $\mathrm{Fe}$ & Total \\
\hline 532 & 0.000 & 100.000 & 0.000 & 0.000 & 100 \\
\hline 536 & 0.000 & 100.000 & 0.000 & 0.000 & 100 \\
\hline 540 & 0.000 & 100.000 & 0.000 & 0.000 & 100 \\
\hline 544 & 0.000 & 100.000 & 0.000 & 0.000 & 100 \\
\hline 548 & 0.000 & 100.000 & 0.000 & 0.000 & 100 \\
\hline 552 & 0.000 & 100.000 & 0.000 & 0.000 & 100 \\
\hline 556 & 0.000 & 99.991 & 0.000 & 0.009 & 100 \\
\hline 560 & 0.000 & 99.998 & 0.000 & 0.002 & 100 \\
\hline 564 & 0.000 & 100.000 & 0.000 & 0.000 & 100 \\
\hline 568 & 0.000 & 100.000 & 0.000 & 0.000 & 100 \\
\hline 572 & 0.000 & 100.000 & 0.000 & 0.000 & 100 \\
\hline 576 & 0.000 & 100.000 & 0.000 & 0.000 & 100 \\
\hline 580 & 0.000 & 100.000 & 0.000 & 0.000 & 100 \\
\hline 584 & 0.000 & 100.000 & 0.000 & 0.000 & 100 \\
\hline 588 & 0.000 & 100.000 & 0.000 & 0.000 & 100 \\
\hline 592 & 0.000 & 100.000 & 0.000 & 0.000 & 100 \\
\hline 596 & 0.000 & 99.990 & 0.000 & 0.010 & 100 \\
\hline 600 & 0.000 & 100.000 & 0.000 & 0.000 & 100 \\
\hline 604 & 0.000 & 100.000 & 0.000 & 0.000 & 100 \\
\hline 608 & 0.000 & 99.998 & 0.000 & 0.002 & 100 \\
\hline 612 & 0.000 & 100.000 & 0.000 & 0.000 & 100 \\
\hline 616 & 0.000 & 100.000 & 0.000 & 0.000 & 100 \\
\hline 620 & 0.000 & 100.000 & 0.000 & 0.000 & 100 \\
\hline 624 & 0.000 & 100.000 & 0.000 & 0.000 & 100 \\
\hline 628 & 0.000 & 99.992 & 0.008 & 0.000 & 100 \\
\hline 632 & 0.000 & 100.000 & 0.000 & 0.000 & 100 \\
\hline 636 & 0.000 & 100.000 & 0.000 & 0.000 & 100 \\
\hline 640 & 0.000 & 100.000 & 0.000 & 0.000 & 100 \\
\hline 644 & 0.000 & 100.000 & 0.000 & 0.000 & 100 \\
\hline 648 & 0.000 & 100.000 & 0.000 & 0.000 & 100 \\
\hline 652 & 0.000 & 100.000 & 0.000 & 0.000 & 100 \\
\hline 656 & 0.000 & 100.000 & 0.000 & 0.000 & 100 \\
\hline 660 & 0.000 & 100.000 & 0.000 & 0.000 & 100 \\
\hline 664 & 0.000 & 100.000 & 0.000 & 0.000 & 100 \\
\hline 668 & 0.000 & 100.000 & 0.000 & 0.000 & 100 \\
\hline 672 & 0.000 & 100.000 & 0.000 & 0.000 & 100 \\
\hline 676 & 0.000 & 100.000 & 0.000 & 0.000 & 100 \\
\hline 680 & 0.000 & 100.000 & 0.000 & 0.000 & 100 \\
\hline 684 & 0.000 & 100.000 & 0.000 & 0.000 & 100 \\
\hline 688 & 0.000 & 100.000 & 0.000 & 0.000 & 100 \\
\hline 692 & 0.000 & 99.993 & 0.000 & 0.007 & 100 \\
\hline 696 & 0.000 & 100.000 & 0.000 & 0.000 & 100 \\
\hline 700 & 0.000 & 100.000 & 0.000 & 0.000 & 100 \\
\hline 704 & 0.000 & 99.990 & 0.000 & 0.010 & 100 \\
\hline 708 & 0.000 & 100.000 & 0.000 & 0.000 & 100 \\
\hline 712 & 0.000 & 100.000 & 0.000 & 0.000 & 100 \\
\hline 716 & 0.000 & 100.000 & 0.000 & 0.000 & 100 \\
\hline 720 & 0.000 & 100.000 & 0.000 & 0.000 & 100 \\
\hline
\end{tabular}




\begin{tabular}{lrrrcr}
\hline $\begin{array}{l}\text { Position } \\
(\boldsymbol{\mu m})\end{array}$ & \multicolumn{5}{c}{ Element } \\
\cline { 2 - 6 } & $\mathbf{C r}$ & \multicolumn{1}{c}{$\mathbf{N i}$} & \multicolumn{1}{c}{ Al } & Fe & Total \\
\hline 724 & 0.000 & 100.000 & 0.000 & 0.000 & 100 \\
728 & 0.000 & 99.991 & 0.009 & 0.000 & 100 \\
732 & 0.000 & 99.977 & 0.000 & 0.023 & 100 \\
736 & 0.000 & 100.000 & 0.000 & 0.000 & 100 \\
740 & 0.000 & 99.975 & 0.000 & 0.025 & 100 \\
744 & 0.000 & 100.000 & 0.000 & 0.000 & 100 \\
748 & 0.000 & 100.000 & 0.000 & 0.000 & 100 \\
752 & 0.000 & 100.000 & 0.000 & 0.000 & 100 \\
756 & 0.000 & 99.976 & 0.024 & 0.000 & 100 \\
760 & 0.000 & 100.000 & 0.000 & 0.000 & 100 \\
764 & 0.000 & 100.000 & 0.000 & 0.000 & 100 \\
768 & 0.000 & 100.000 & 0.000 & 0.000 & 100 \\
772 & 0.000 & 100.000 & 0.000 & 0.000 & 100 \\
776 & 0.000 & 99.997 & 0.000 & 0.003 & 100 \\
780 & 0.000 & 100.000 & 0.000 & 0.000 & 100 \\
784 & 0.000 & 100.000 & 0.000 & 0.000 & 100 \\
788 & 0.000 & 100.000 & 0.000 & 0.000 & 100 \\
792 & 0.000 & 100.000 & 0.000 & 0.000 & 100 \\
796 & 0.000 & 99.991 & 0.000 & 0.009 & 100 \\
800 & 0.000 & 99.997 & 0.000 & 0.003 & 100
\end{tabular}


The location of the elemental line scan across a gap at the interface and the position of the interface between Alloy 214 and the nickel cladding are shown in Fig. A.1. The associated chemical information, obtained via wavelength-dispersive spectroscopy, is presented in Fig. A.2. The normalized atom percentage data are presented in Table A.2.

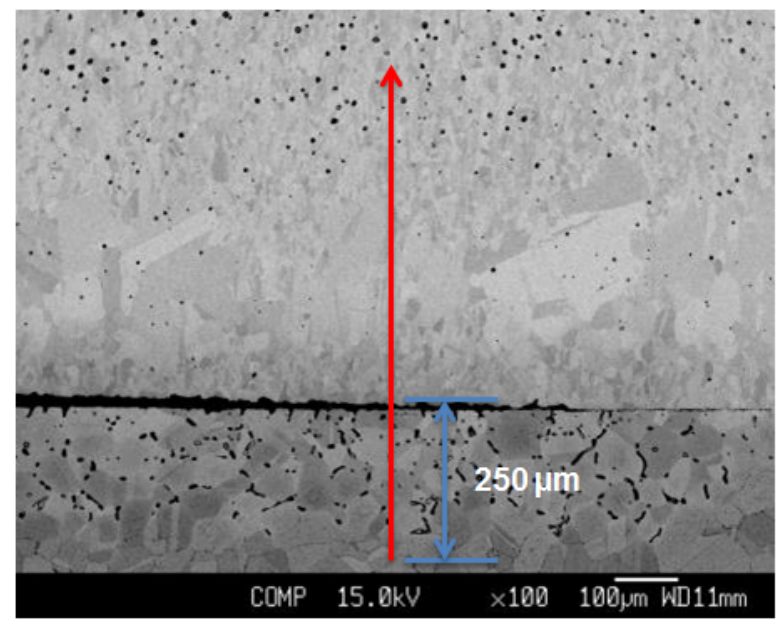

Fig. A.1. Image showing location of the elemental line scan across a gap in the interface (red arrow) and position of the interface between Alloy 214 and the nickel cladding with respect to the start of the line scan (blue arrow). 


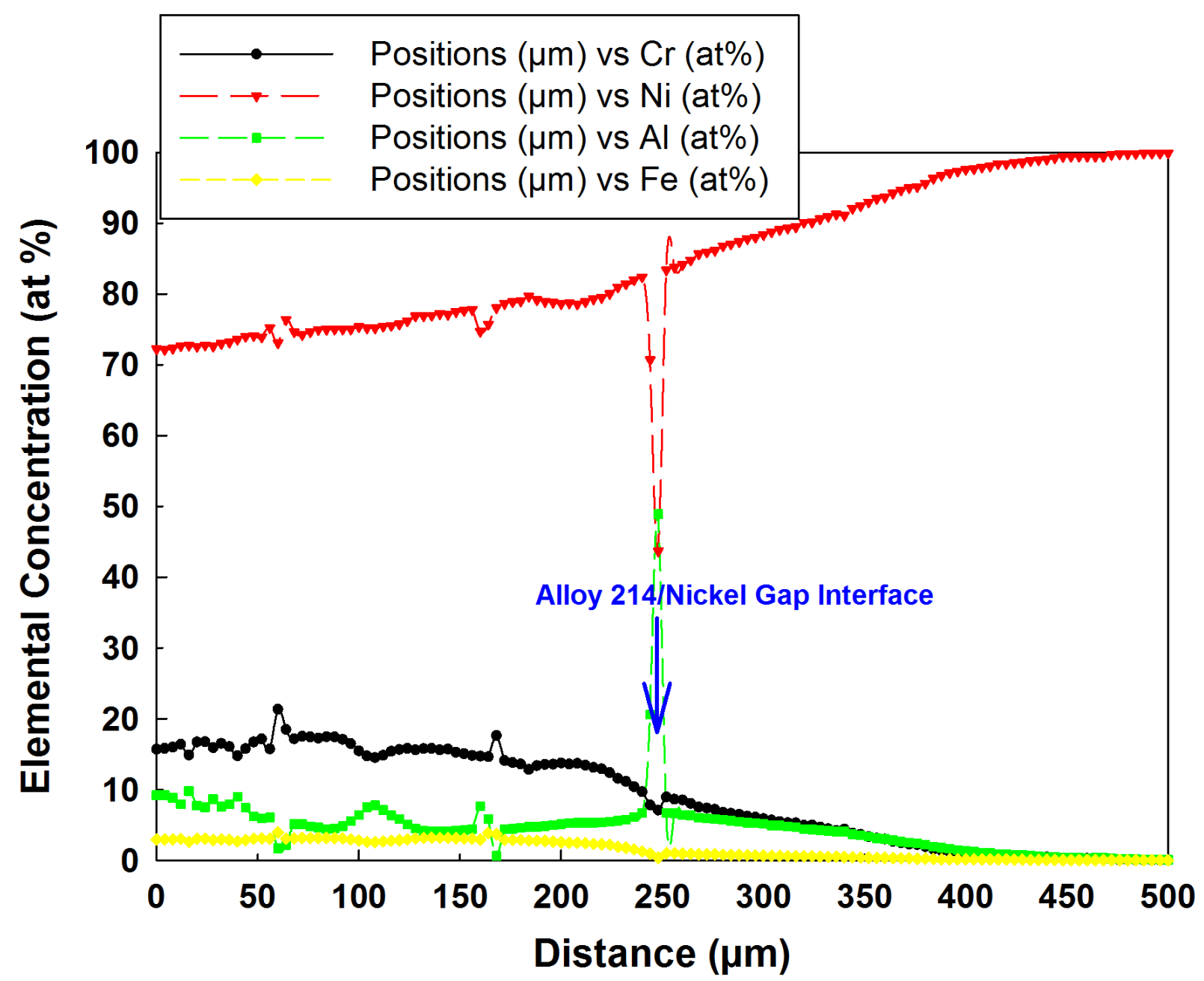

Fig. A.2. Normalized elemental concentration (at $\%$ ) as a function of distance across gap interface. The interface between Alloy 214 and the nickel cladding (blue arrow) is at 250 $\mu \mathrm{m}$.

Table A2. Elemental concentration (at. \%) across gap interface of Alloy 214 and nickel cladding

\begin{tabular}{lccccr}
\hline $\begin{array}{l}\text { Position } \\
\text { (um) }\end{array}$ & \multicolumn{5}{c}{ Element } \\
\cline { 2 - 6 } & $\mathbf{C r}$ & $\mathbf{N i}$ & $\mathbf{A l}$ & $\mathbf{F e}$ & Total \\
\hline 0 & 15.670 & 72.215 & 9.177 & 2.939 & 100 \\
4 & 15.774 & 72.125 & 9.173 & 2.928 & 100 \\
8 & 15.970 & 72.299 & 8.801 & 2.929 & 100 \\
12 & 16.386 & 72.668 & 7.921 & 3.025 & 100 \\
16 & 14.864 & 72.727 & 9.781 & 2.628 & 100 \\
20 & 16.695 & 72.559 & 7.713 & 3.034 & 100 \\
24 & 16.741 & 72.765 & 7.458 & 3.036 & 100 \\
28 & 15.888 & 72.622 & 8.640 & 2.850 & 100 \\
32 & 16.490 & 73.000 & 7.580 & 2.930 & 100 \\
36 & 16.044 & 73.164 & 7.918 & 2.874 & 100
\end{tabular}




\begin{tabular}{|c|c|c|c|c|c|}
\hline \multirow{2}{*}{$\begin{array}{l}\text { Position } \\
\text { (um) }\end{array}$} & \multicolumn{5}{|c|}{ Element } \\
\hline & $\mathrm{Cr}$ & $\mathbf{N i}$ & $\mathrm{Al}$ & Fe & Total \\
\hline 40 & 14.755 & 73.584 & 8.976 & 2.684 & 100 \\
\hline 44 & 15.758 & 73.992 & 7.407 & 2.843 & 100 \\
\hline 48 & 16.690 & 74.091 & 6.175 & 3.044 & 100 \\
\hline 52 & 17.132 & 73.898 & 5.891 & 3.079 & 100 \\
\hline 56 & 15.735 & 75.203 & 6.029 & 3.033 & 100 \\
\hline 60 & 21.320 & 73.064 & 1.671 & 3.946 & 100 \\
\hline 64 & 18.465 & 76.344 & 2.136 & 3.055 & 100 \\
\hline 68 & 17.161 & 74.647 & 5.086 & 3.105 & 100 \\
\hline 72 & 17.498 & 74.243 & 5.094 & 3.165 & 100 \\
\hline 76 & 17.415 & 74.657 & 4.795 & 3.132 & 100 \\
\hline 80 & 17.236 & 74.953 & 4.646 & 3.165 & 100 \\
\hline 84 & 17.446 & 74.987 & 4.396 & 3.171 & 100 \\
\hline 88 & 17.404 & 75.015 & 4.458 & 3.122 & 100 \\
\hline 92 & 17.063 & 75.025 & 4.821 & 3.091 & 100 \\
\hline 96 & 16.480 & 75.008 & 5.545 & 2.967 & 100 \\
\hline 100 & 15.437 & 75.362 & 6.422 & 2.779 & 100 \\
\hline 104 & 14.717 & 75.192 & 7.512 & 2.579 & 100 \\
\hline 108 & 14.512 & 75.179 & 7.761 & 2.547 & 100 \\
\hline 112 & 14.804 & 75.423 & 7.103 & 2.670 & 100 \\
\hline 116 & 15.375 & 75.523 & 6.356 & 2.745 & 100 \\
\hline 120 & 15.645 & 75.715 & 5.836 & 2.804 & 100 \\
\hline 124 & 15.799 & 76.188 & 5.066 & 2.947 & 100 \\
\hline 128 & 15.589 & 76.862 & 4.487 & 3.061 & 100 \\
\hline 132 & 15.760 & 76.912 & 4.160 & 3.167 & 100 \\
\hline 136 & 15.797 & 76.964 & 4.058 & 3.181 & 100 \\
\hline 140 & 15.583 & 77.220 & 4.043 & 3.154 & 100 \\
\hline 144 & 15.701 & 77.105 & 4.032 & 3.162 & 100 \\
\hline 148 & 15.257 & 77.464 & 4.172 & 3.106 & 100 \\
\hline 152 & 15.051 & 77.652 & 4.237 & 3.059 & 100 \\
\hline 156 & 14.781 & 77.795 & 4.395 & 3.029 & 100 \\
\hline 160 & 14.714 & 74.710 & 7.636 & 2.940 & 100 \\
\hline 164 & 14.605 & 75.687 & 5.855 & 3.853 & 100 \\
\hline 168 & 17.618 & 78.043 & 0.627 & 3.712 & 100 \\
\hline 172 & 14.085 & 78.650 & 4.388 & 2.877 & 100 \\
\hline 176 & 13.787 & 78.877 & 4.452 & 2.884 & 100 \\
\hline 180 & 13.572 & 78.975 & 4.575 & 2.879 & 100 \\
\hline 184 & 12.816 & 79.672 & 4.718 & 2.794 & 100 \\
\hline 188 & 13.363 & 79.167 & 4.725 & 2.745 & 100 \\
\hline 192 & 13.521 & 78.921 & 4.826 & 2.733 & 100 \\
\hline 196 & 13.571 & 78.812 & 4.970 & 2.647 & 100 \\
\hline 200 & 13.729 & 78.626 & 5.096 & 2.549 & 100 \\
\hline 204 & 13.587 & 78.701 & 5.235 & 2.476 & 100 \\
\hline 208 & 13.659 & 78.554 & 5.303 & 2.484 & 100 \\
\hline 212 & 13.406 & 78.880 & 5.302 & 2.412 & 100 \\
\hline 216 & 13.093 & 79.295 & 5.303 & 2.308 & 100 \\
\hline 220 & 12.904 & 79.508 & 5.327 & 2.260 & 100 \\
\hline 224 & 12.346 & 80.048 & 5.431 & 2.175 & 100 \\
\hline 228 & 11.567 & 80.958 & 5.577 & 1.899 & 100 \\
\hline
\end{tabular}




\begin{tabular}{lrrrrr}
\hline Position & \multicolumn{5}{c}{ Element } \\
\cline { 2 - 6 } (um) & \multicolumn{1}{c}{ Cr } & \multicolumn{1}{c}{ Ni } & \multicolumn{1}{c}{ Al } & Fe & Total \\
\hline 232 & 11.123 & 81.411 & 5.718 & 1.747 & 100 \\
236 & 10.398 & 81.985 & 6.097 & 1.520 & 100 \\
240 & 9.672 & 82.374 & 6.702 & 1.251 & 100 \\
244 & 7.782 & 70.702 & 20.588 & 0.928 & 100 \\
248 & 7.072 & 43.680 & 48.889 & 0.359 & 100 \\
252 & 8.930 & 83.373 & 6.704 & 0.994 & 100 \\
256 & 8.626 & 83.758 & 6.640 & 0.976 & 100 \\
260 & 8.512 & 84.139 & 6.425 & 0.924 & 100 \\
264 & 8.005 & 84.751 & 6.341 & 0.904 & 100 \\
268 & 7.503 & 85.630 & 6.013 & 0.855 & 100 \\
272 & 7.353 & 85.889 & 5.921 & 0.837 & 100 \\
276 & 7.195 & 86.164 & 5.818 & 0.823 & 100 \\
280 & 6.762 & 86.758 & 5.714 & 0.766 & 100 \\
284 & 6.627 & 87.033 & 5.597 & 0.743 & 100 \\
288 & 6.471 & 87.352 & 5.450 & 0.727 & 100 \\
292 & 6.202 & 87.797 & 5.297 & 0.704 & 100 \\
296 & 6.076 & 87.997 & 5.265 & 0.662 & 100 \\
300 & 5.881 & 88.349 & 5.126 & 0.644 & 100 \\
304 & 5.680 & 88.766 & 4.930 & 0.624 & 100 \\
308 & 5.434 & 89.065 & 4.889 & 0.612 & 100 \\
312 & 5.309 & 89.313 & 4.797 & 0.581 & 100 \\
316 & 5.276 & 89.447 & 4.711 & 0.566 & 100 \\
320 & 4.924 & 90.094 & 4.427 & 0.555 & 100 \\
324 & 4.958 & 90.126 & 4.358 & 0.558 & 100 \\
328 & 4.673 & 90.584 & 4.236 & 0.507 & 100 \\
332 & 4.447 & 90.926 & 4.145 & 0.482 & 100 \\
336 & 4.197 & 91.279 & 4.036 & 0.489 & 100 \\
340 & 4.382 & 91.088 & 4.081 & 0.449 & 100 \\
344 & 3.826 & 92.080 & 3.672 & 0.421 & 100 \\
348 & 3.654 & 92.445 & 3.525 & 0.376 & 100 \\
352 & 3.319 & 92.969 & 3.342 & 0.370 & 100 \\
356 & 3.103 & 93.457 & 3.109 & 0.330 & 100 \\
360 & 2.973 & 93.677 & 3.005 & 0.344 & 100 \\
364 & 2.673 & 94.226 & 2.805 & 0.297 & 100 \\
368 & 2.468 & 94.658 & 2.612 & 0.262 & 100 \\
372 & 2.259 & 94.989 & 2.487 & 0.265 & 100 \\
376 & 2.212 & 95.140 & 2.423 & 0.226 & 100 \\
380 & 1.940 & 95.607 & 2.219 & 0.234 & 100 \\
384 & 1.567 & 96.319 & 1.934 & 0.180 & 100 \\
388 & 1.344 & 96.736 & 1.770 & 0.150 & 100 \\
392 & 1.155 & 97.089 & 1.613 & 0.144 & 100 \\
396 & 1.123 & 97.332 & 1.407 & 0.139 & 100 \\
400 & 0.977 & 97.590 & 1.305 & 0.128 & 100 \\
404 & 0.929 & 97.683 & 1.270 & 0.119 & 100 \\
408 & 0.910 & 97.900 & 1.079 & 0.110 & 100 \\
412 & 0.823 & 98.053 & 1.028 & 0.096 & 100 \\
420 & 0.652 & 98.386 & 0.870 & 0.092 & 100 \\
& 0.692 & 98.398 & 0.821 & 0.089 & 100
\end{tabular}




\begin{tabular}{lrrrrr}
\hline Position & \multicolumn{5}{c}{ Element } \\
\cline { 2 - 6 } (um) & Cr & \multicolumn{1}{c}{ Ni } & Al & Fe & Total \\
\hline 424 & 0.618 & 98.518 & 0.791 & 0.073 & 100 \\
428 & 0.584 & 98.599 & 0.749 & 0.068 & 100 \\
432 & 0.515 & 98.807 & 0.625 & 0.053 & 100 \\
436 & 0.437 & 98.927 & 0.597 & 0.039 & 100 \\
440 & 0.444 & 99.018 & 0.503 & 0.034 & 100 \\
444 & 0.295 & 99.219 & 0.457 & 0.030 & 100 \\
448 & 0.224 & 99.381 & 0.368 & 0.028 & 100 \\
452 & 0.194 & 99.410 & 0.371 & 0.025 & 100 \\
456 & 0.218 & 99.418 & 0.339 & 0.026 & 100 \\
460 & 0.242 & 99.426 & 0.305 & 0.028 & 100 \\
464 & 0.244 & 99.402 & 0.336 & 0.019 & 100 \\
468 & 0.237 & 99.407 & 0.343 & 0.013 & 100 \\
472 & 0.073 & 99.674 & 0.240 & 0.014 & 100 \\
476 & 0.028 & 99.746 & 0.215 & 0.011 & 100 \\
480 & 0.047 & 99.775 & 0.178 & 0.000 & 100 \\
484 & 0.026 & 99.814 & 0.147 & 0.013 & 100 \\
488 & 0.004 & 99.860 & 0.136 & 0.000 & 100 \\
492 & 0.009 & 99.848 & 0.139 & 0.005 & 100 \\
496 & 0.026 & 99.855 & 0.111 & 0.009 & 100 \\
500 & 0.028 & 99.904 & 0.069 & 0.000 & 100 \\
504 & 0.038 & 99.891 & 0.071 & 0.000 & 100 \\
508 & 0.051 & 99.827 & 0.101 & 0.021 & 100 \\
512 & 0.000 & 99.924 & 0.067 & 0.009 & 100 \\
516 & 0.000 & 99.953 & 0.044 & 0.003 & 100 \\
520 & 0.004 & 99.907 & 0.089 & 0.000 & 100 \\
524 & 0.000 & 99.981 & 0.016 & 0.003 & 100 \\
528 & 0.000 & 99.988 & 0.013 & 0.000 & 100 \\
532 & 0.000 & 99.954 & 0.047 & 0.000 & 100 \\
536 & 0.000 & 99.973 & 0.016 & 0.011 & 100 \\
540 & 0.000 & 99.979 & 0.021 & 0.001 & 100 \\
544 & 0.000 & 100.000 & 0.000 & 0.000 & 100 \\
548 & 0.000 & 100.000 & 0.000 & 0.000 & 100 \\
552 & 0.000 & 100.000 & 0.000 & 0.000 & 100 \\
556 & 0.000 & 100.000 & 0.000 & 0.000 & 100 \\
560 & 0.000 & 99.991 & 0.009 & 0.001 & 100 \\
564 & 0.000 & 99.998 & 0.000 & 0.002 & 100 \\
568 & 0.000 & 99.993 & 0.000 & 0.007 & 100 \\
572 & 0.000 & 99.993 & 0.007 & 0.000 & 100 \\
576 & 0.000 & 99.866 & 0.134 & 0.000 & 100 \\
580 & 0.000 & 99.997 & 0.000 & 0.003 & 100 \\
584 & 0.000 & 99.995 & 0.005 & 0.000 & 100 \\
588 & 0.000 & 100.000 & 0.000 & 0.000 & 100 \\
592 & 0.000 & 100.000 & 0.000 & 0.000 & 100 \\
596 & 0.000 & 100.000 & 0.000 & 0.000 & 100 \\
612 & 0.000 & 99.994 & 0.000 & 0.006 & 100 \\
& 0.000 & 99.987 & 0.013 & 0.000 & 100 \\
604 & 0.000 & 100.000 & 0.000 & 0.000 & 100 \\
50 & 0.000 & 99.978 & 0.012 & 0.010 & 100
\end{tabular}




\begin{tabular}{lrrrrr}
\hline Position & \multicolumn{5}{c}{ Element } \\
(um) & Cr & \multicolumn{1}{c}{ Ni } & Al & Fe & Total \\
\hline 616 & 0.000 & 99.998 & 0.000 & 0.002 & 100 \\
620 & 0.000 & 99.999 & 0.000 & 0.001 & 100 \\
624 & 0.000 & 100.000 & 0.000 & 0.000 & 100 \\
628 & 0.000 & 100.000 & 0.000 & 0.000 & 100 \\
632 & 0.000 & 100.000 & 0.000 & 0.000 & 100 \\
636 & 0.000 & 100.000 & 0.000 & 0.000 & 100 \\
640 & 0.000 & 100.000 & 0.000 & 0.000 & 100 \\
644 & 0.000 & 100.000 & 0.000 & 0.000 & 100 \\
648 & 0.000 & 100.000 & 0.000 & 0.000 & 100 \\
652 & 0.000 & 100.000 & 0.000 & 0.000 & 100 \\
656 & 0.000 & 99.998 & 0.000 & 0.002 & 100 \\
660 & 0.000 & 99.999 & 0.002 & 0.000 & 100 \\
664 & 0.000 & 99.999 & 0.000 & 0.001 & 100 \\
668 & 0.000 & 100.000 & 0.000 & 0.000 & 100 \\
672 & 0.000 & 100.000 & 0.000 & 0.000 & 100 \\
676 & 0.000 & 100.000 & 0.000 & 0.000 & 100 \\
680 & 0.000 & 99.997 & 0.000 & 0.003 & 100 \\
684 & 0.000 & 100.000 & 0.000 & 0.000 & 100 \\
688 & 0.000 & 100.000 & 0.000 & 0.000 & 100 \\
692 & 0.000 & 100.000 & 0.000 & 0.000 & 100 \\
696 & 0.000 & 99.980 & 0.000 & 0.020 & 100 \\
700 & 0.000 & 100.000 & 0.000 & 0.000 & 100 \\
704 & 0.000 & 99.993 & 0.007 & 0.000 & 100 \\
708 & 0.000 & 100.000 & 0.000 & 0.000 & 100 \\
712 & 0.000 & 100.000 & 0.000 & 0.000 & 100 \\
716 & 0.000 & 100.000 & 0.000 & 0.000 & 100 \\
720 & 0.000 & 100.000 & 0.000 & 0.000 & 100 \\
724 & 0.000 & 100.000 & 0.000 & 0.000 & 100 \\
728 & 0.000 & 100.000 & 0.000 & 0.000 & 100 \\
732 & 0.000 & 100.000 & 0.000 & 0.000 & 100 \\
736 & 0.000 & 100.000 & 0.000 & 0.000 & 100 \\
740 & 0.000 & 100.000 & 0.000 & 0.000 & 100 \\
744 & 0.000 & 100.000 & 0.000 & 0.000 & 100 \\
748 & 0.000 & 100.000 & 0.000 & 0.000 & 100 \\
752 & 0.000 & 100.000 & 0.000 & 0.000 & 100 \\
756 & 0.000 & 100.000 & 0.000 & 0.000 & 100 \\
760 & 0.000 & 99.998 & 0.000 & 0.002 & 100 \\
764 & 0.000 & 100.000 & 0.000 & 0.000 & 100 \\
768 & 0.000 & 99.992 & 0.000 & 0.008 & 100 \\
772 & 0.000 & 99.993 & 0.000 & 0.007 & 100 \\
776 & 0.000 & 100.000 & 0.000 & 0.000 & 100 \\
780 & 0.000 & 100.000 & 0.000 & 0.000 & 100 \\
784 & 0.000 & 100.000 & 0.000 & 0.000 & 100 \\
788 & 0.000 & 100.000 & 0.000 & 0.000 & 100 \\
792 & 0.000 & 99.999 & 0.000 & 0.001 & 100 \\
796 & 0.000 & 100.000 & 0.000 & 0.000 & 100 \\
800 & 0.000 & 99.996 & 0.000 & 0.004 & 100
\end{tabular}

